\title{
Archaeological applications of polynomial texture mapping: analysis, conservation and representation
}

\author{
Graeme Earl $^{\mathrm{a}, *}$, Kirk Martinez ${ }^{\mathrm{b}}$, Tom Malzbender ${ }^{\mathrm{c}}$ \\ a Archaeological Computing Research Group, School of Humanities, University of Southampton, Southampton, Hampshire SO17IBF, UK \\ ${ }^{\mathrm{b}}$ School of Electronics and Computer Science, University of Southampton, UK \\ ${ }^{\mathrm{c}}$ Hewlett-Packard Laboratories, Palo Alto, CA 94304-1126, USA
}

\section{A R T I C L E I N F O}

Article history:

Received 2 November 2009

Received in revised form

15 March 2010

Accepted 17 March 2010

\section{Keywords:}

Polynomial texture mapping

PTM

RTI

Imaging

Scanning

Surface recording

Conservation

Computer graphics

\begin{abstract}
A B S T R A C T
Polynomial Texture Mapping is an image capture and processing technique that was developed by HP Labs in 2000. It enables the recording and representation of subtle surface details using a standard digital camera and lighting, and software that is free for non-commercial use. Cultural heritage applications have been associated with the technology from its earliest stages, including examples in areas such as cuneiform, numismatics, rock art, lithics and Byzantine art. The paper begins by outlining the technical principles involved. It then brings together the extant work in the field. Through examples developed by the University of Southampton in partnership with a range of UK and international bodies it demonstrates the benefits of the technology in the areas of archaeological analysis, conservation and representation. Finally it considers the future possibilities of this technology and ongoing developments.
\end{abstract}

(C) 2010 Elsevier Ltd. All rights reserved.

\section{Introduction}

Polynomial Texture Mapping (hereafter PTM) is an image capture and processing technique that was first published in a technical report by HP Labs in 2000 (Malzbender et al., 2000; Malzbender and Gelb, 2001). It then received full peer review publication to considerable impact in an Association for Computer Machinery Special Interest Group in Graphics and Interactive Techniques (SIGGRAPH) publication in 2001 (Malzbender et al., 2001). The technique enables the recording and representation of subtle surface details using a standard digital camera at constant exposure and varying lighting, and is one implementation of the general approach of Reflectance Transformation Imaging (hereafter RTI) also defined by Malzbender et al. (2001) which captures the broad range of reflectance characteristics for any surface. The PTM file format can be produced from standard digital photographs, subjected to image processing technologies for enhancing surface detail and for identifying optimal lighting configuration, and digitally relit as if from one or more light sources distributed around the image plane on a hemisphere.

\footnotetext{
* Corresponding author. Tel.: +44 7787522070 .

E-mail address: graeme.earl@soton.ac.uk (G. Earl).
}

From its inception the technique was recognized to have cultural heritage significance, with one case study in the 2001 paper being a neo-Sumerian tablet from c. 2000 BC. The PTM technique was proven to provide better representation and decipherment of illustrative and cuneiform components (Malzbender et al., 2000). Cultural heritage applications have now begun to be seen in areas such as cuneiform, epigraphy and other written material (Lundberg, 2006; Willems et al., 2005; Zuckerman, 2004; Web1; Web2; Web3), numismatics, portable rock art and lithic studies, and now include larger objects such as complete rock art panels, ${ }^{1}$ sarcophagi and architectural fragments. Most recently the technique has been embedded in ongoing excavation projects (Earl et al., forthcoming) and is being trialled by an archaeological field unit (Web4). This growth of applications and of technologies has been spearheaded by Cultural Heritage Imaging, a US nonprofit corporation who have recently produced a new suite of RTI capturing, fitting and viewing tools (Web5).

\footnotetext{
${ }^{1}$ Fiona Gamble from the ACRG has used the highlight-based approach to record rock art sites at Torbhlaren, Aygyll and Ben Lawers at Perth and Kinross, Scotland. The PTM was used to provide a record of the rock art as it was exposed and also to enable the digital recreation of the rock art in simulated contexts. This in turn enabled the art to be relit according to the lighting orientation at different times of the day and year in prehistory and today.
} 


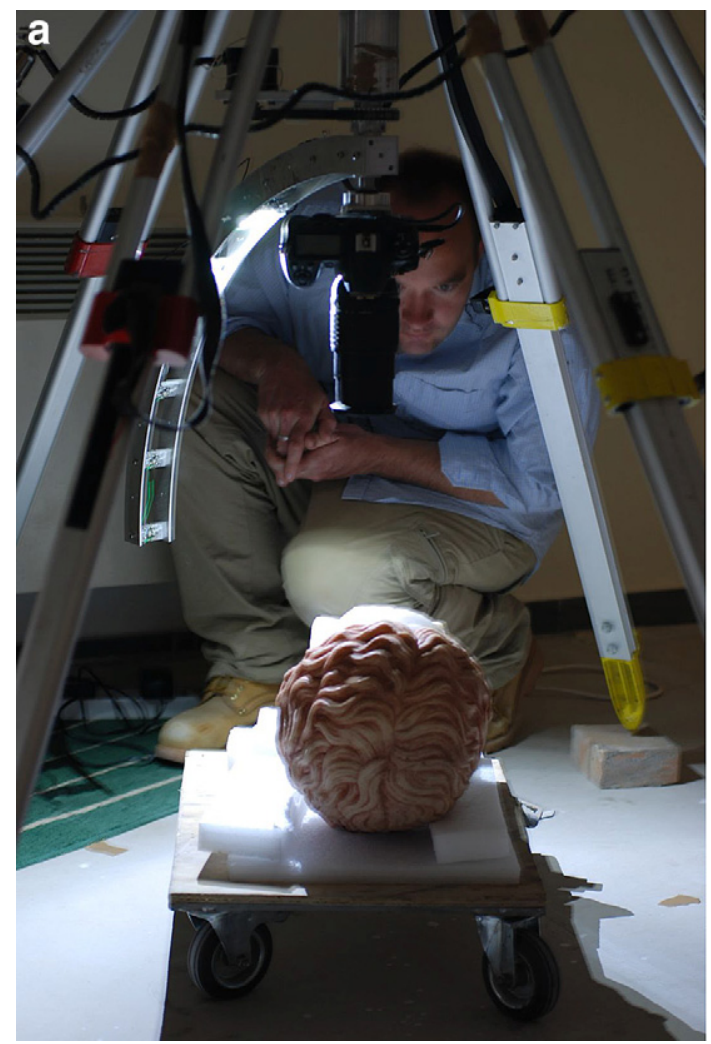

b

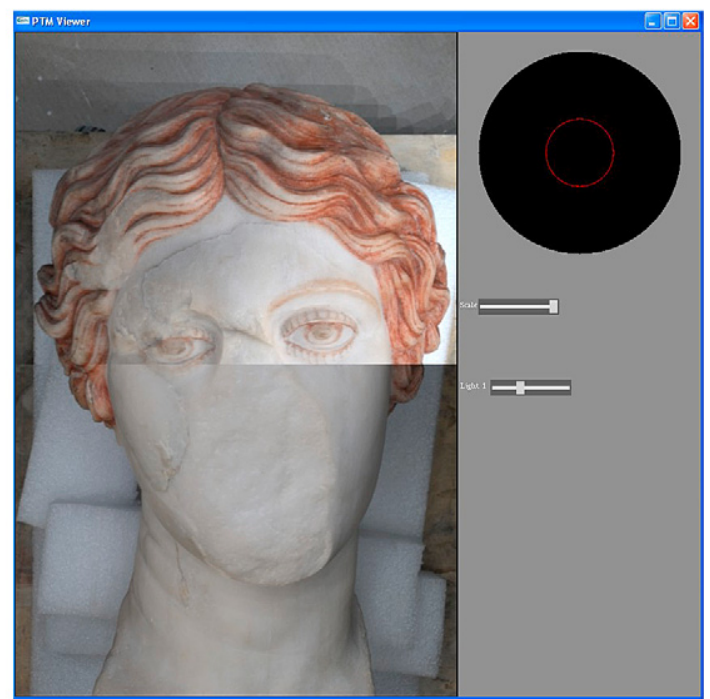

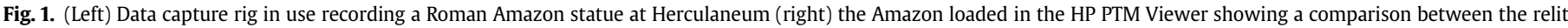
PTM (top) and a standard computer graphic approximation to surface illumination (below).

Researchers involved in PTM application and development, which today still constitutes a relatively small group, believe that the technique deserves far wider attention. Furthermore, recent advances mean that it is much more easily available to all archaeologists in practically any working context. This paper begins by

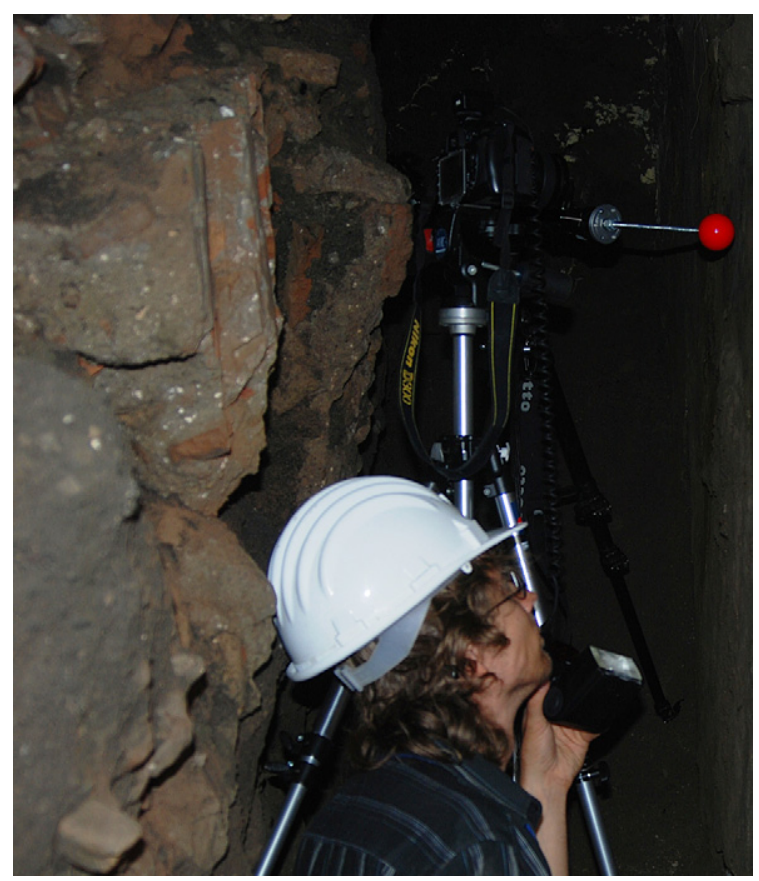

Fig. 2. Highlight-based capture system in use in tunnels at Herculaneum. outlining the technical principles involved. It then brings together the extant work in the field. Through examples developed by the University of Southampton it demonstrates the benefits of the technology in the areas of archaeological analysis, conservation and representation. Finally it considers the future possibilities of this technology and ongoing developments.

\section{Technical background and development}

The PTM is a representation of varying luminance of pixels in a sampled image plane. The method uses a fixed camera and captured surface (frequently a single object), and varying light positions known either from creation of a fixed light orientation device (e.g. a lighting dome) or through calculation of incident light direction using data present in the images (e.g. one or more shiny spheres). A series of photographs is produced (commonly of the order of 40-80) each with a separate known light source. The variance in the pattern of light and shade across the object is calculated from them (Fig. 1). As chromaticity can be considered to vary by a limited degree as a function of incident light direction (for most materials) the PTM approach based on LRGB PTMs produces an unscaled single value for each red, green and blue channel per pixel. The luminance value, which is the main variable as incident light changes, is stored per sample image per pixel, and computed interactively from the lighting direction using a low order polynomial model. ${ }^{2}$

\footnotetext{
${ }^{2}$ Some materials induce colour changes as a function of lighting direction, for these the RGB PTM format is available, which is capable of modelling such colour changes by modelling each Red, Green and Blue channel independently. The case of changing surface properties with changing viewer direction is mentioned below in the context of BRDF.
} 


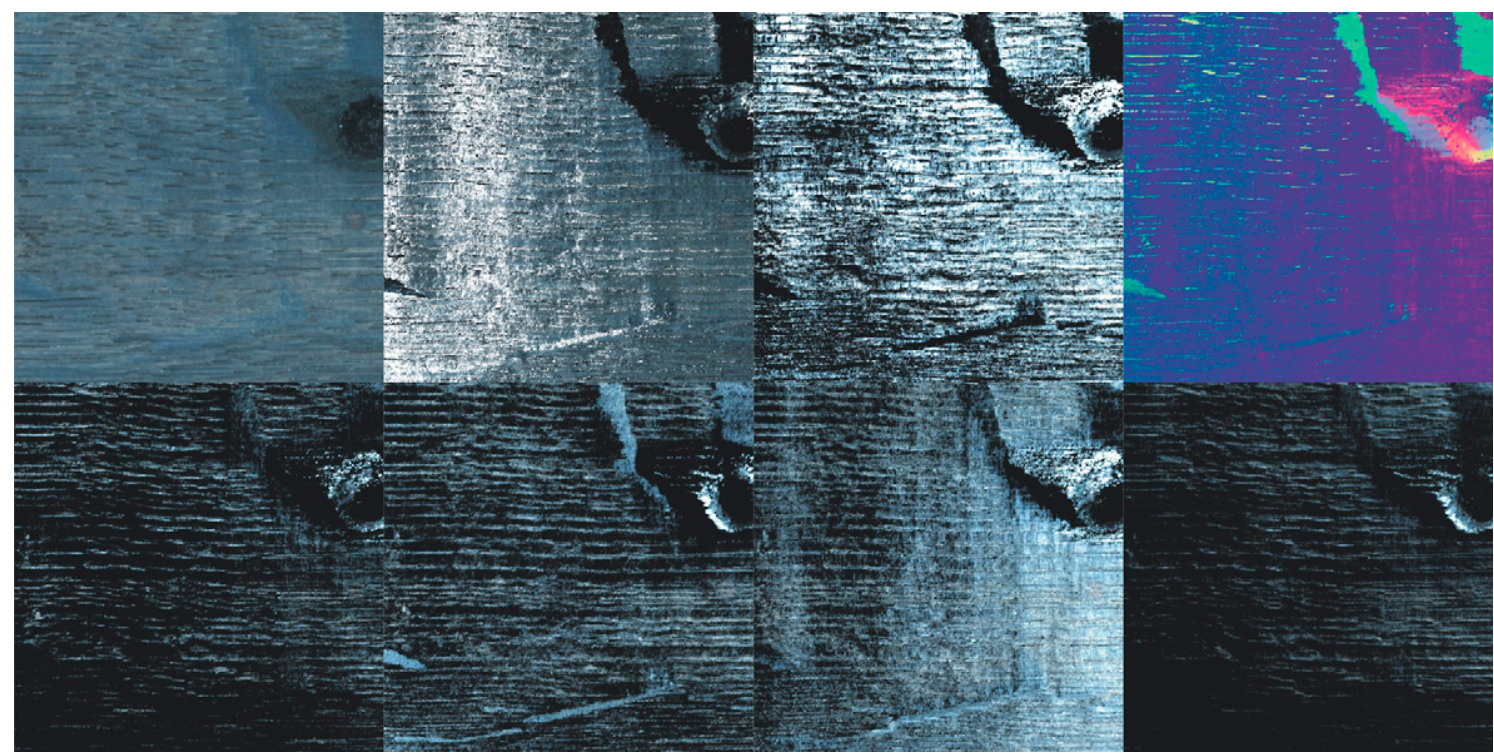

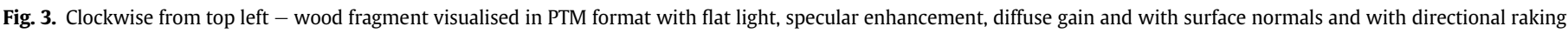
lights (from right, below, left and above).

As a consequence the HP PTM Viewer software, its web-based equivalent and the more recent RTI Viewer enable interactive visualisation of all pixels under any incident light direction. In cultural heritage terms this enables a surface or object to be virtually relit and examined long after it has been recorded and potentially destroyed. Such relighting enables enhanced perception of surface details, as a consequence of varying the incident light direction and in particular by the use of low grazing angles of light to accentuate surface relief. This is particular useful where the surface detail is extremely subtle, or has been damaged through chemical or other erosion, weathering and so on. It benefits from the considerable familiarity of the raking light technique amongst specialists such as epigraphers. Thus, writing tablets with very shallow scratched markings can be read, cracking across surfaces can be defined and monitored, and surface components can be isolated from the background for analysis. Mudge presents a particularly clear demonstration of the technique in the context of numismatics (Mudge et al., 2005). In particular this work demonstrates that whether the surface recorded is diffuse (matte) or highly specular (shiny) in nature the PTM is able to provide an accurate representation of the surface properties and hence appearance under varying light conditions.

The PTM dataset can be combined with standard computer graphics and image processing algorithms to highlight particular forms of information. Archaeologically these have very considerable potential, as shown in the examples below. Diffuse gain is the artificial variation of the diffuse reflectance properties of each pixel (Malzbender et al., 2000). This varies contrast between neighbouring pixels. Specular enhancement uses the surface normals and a specular shading method to make the object recorded artificially

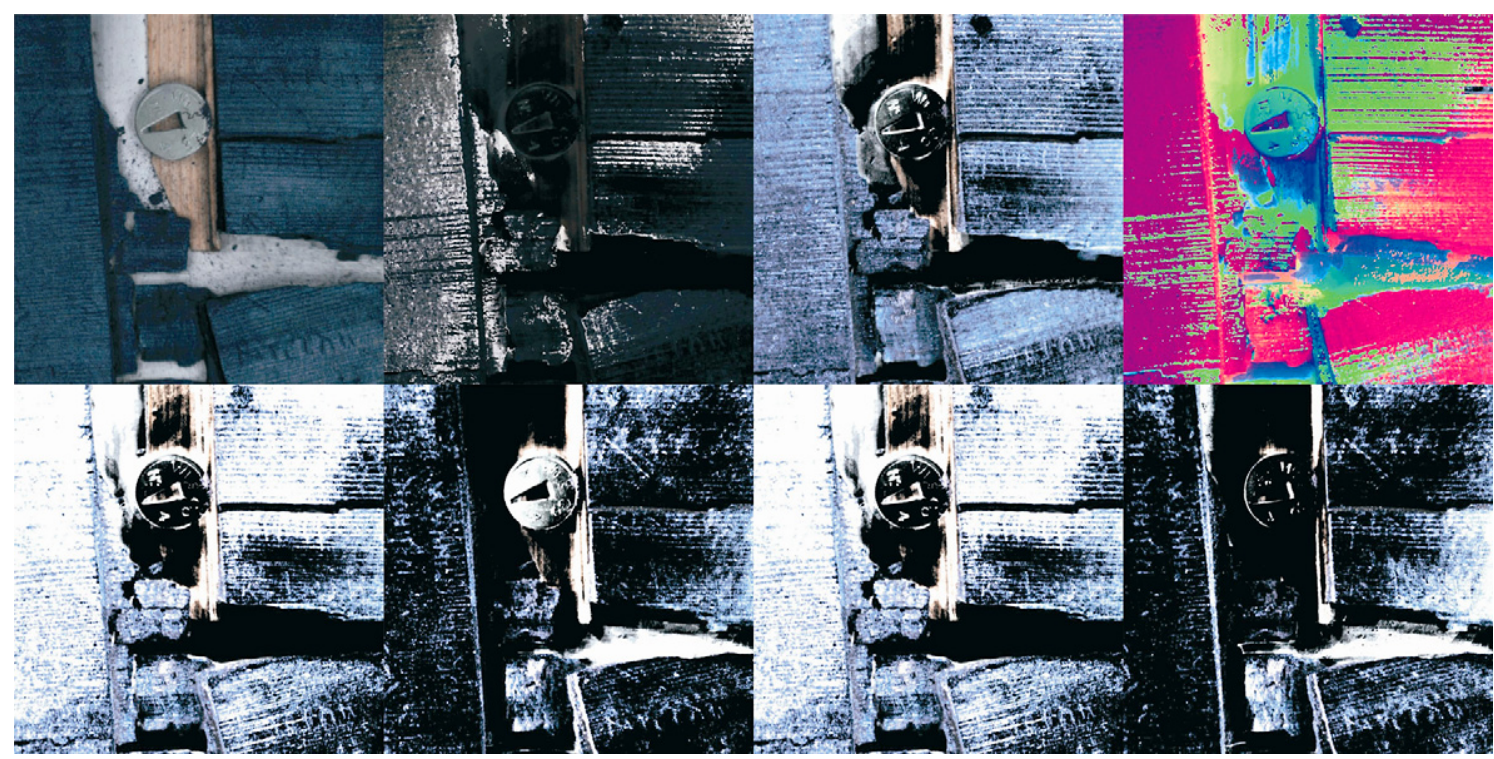

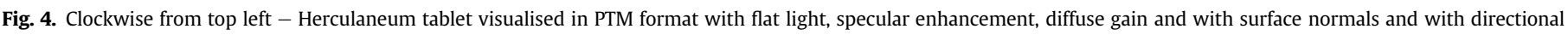
raking lights (from right, below, left and above).

Please cite this article in press as: Earl, G., et al., Archaeological applications of polynomial texture mapping: analysis, conservation and representation, J. Archaeol. Sci. (2010), doi:10.1016/j.jas.2010.03.009 


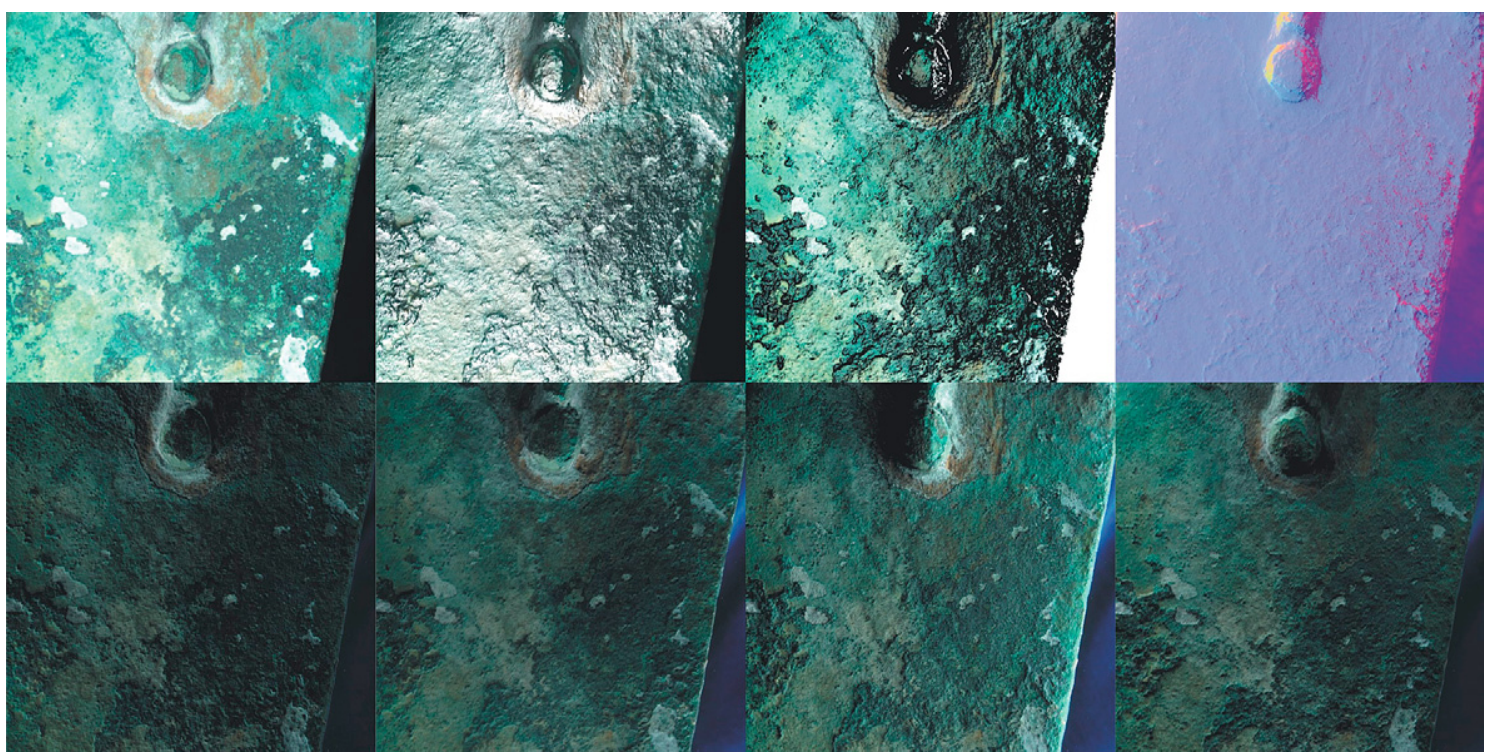

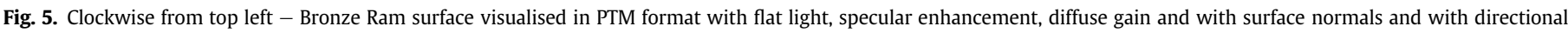
raking lights (from right, below, left and above).

shiny. Light direction extrapolation enables the PTM data to be displayed as if the light source were considerably more grazing than it was during capture, and in turn allows representation of far more obliquely sloping light positions than can be physically realized. Examples of these approaches may be seen in the figures below.

In addition to colour and impact of lighting the PTM enables details about the shape of an object to be defined. The PTM dataset provides estimation of surface normals - the direction in which the surface represented by each pixel can be said to face. The method assumes a diffuse surface and compares luminance values of each pixel to the maximum recovered in order to approximate to surface inclination and relative depth. This work draws on a large body of literature in what is termed photometric stereo, an approach introduced in 1980 (Woodham, 1980). A series of examples from palaeontology demonstrates how these data were in turn used to fit a true three-dimensional surface to the estimated normals (see Hammer et al., 2002: Fig. 11). Such three-dimensional data can then be used for analysis, including surface analysis, cross-sectioning, and automatic identification of surface details, or indeed for augmentation and visualisation using conventional graphics techniques.

\subsection{Creating PTM datasets}

In our capture pipeline at the University of Southampton we employ two standard PTM generation techniques: a rotating arc of lights and the PTMBuilder and RTIBuilder highlight-based approaches (Barbosa et al., 2007; Malzbender and Gelb, 2001). The use of fixed domes or various configurations of lighting arcs is well documented, with most examples capturing visual data via a digital SLR but others employing high speed video (for examples see Hawkins et al., 2001; Wenger et al., 2005; Malzbender et al., 2001; Mudge et al., 2005). We use a comparable system to these, with two separate tripods covered in blackout fabric to enable capture without need for a dark room. One supports a Nikon digital SLR and the second a motorized rotating arc. This has mounts for up to sixteen low-output LED light sources but in our standard setup we commonly use seven or eight. Crucially the camera and arc are physically separated to ensure no motion in the camera. The stepper motor, firing the camera and lights, downloading images, and batch processing are controlled by custom software, whilst camera settings are modified via the Nikon Camera Control Pro 2 software. The process is fully automated and depending on lens settings, depth of field and hence exposure time takes between approximately one and five minutes per standard 56-64 sample capture. Data are either processed in parallel with a separate laptop receiving data, or as a scripted batch process run at the end of the capture session. The considerable advantages of this approach over the highlight method described below are its flexibility in terms of configuration of lights and number of samples per rotation and its automated, rapid capture process. The disadvantages are the need to ensure absolute stability and the separation between the camera and arc components, the limited options for variation in light orientation in the $\mathrm{XZ}$ plane, and the limitations of object capture size imposed by the rig.

The second technique for PTM capture requires no fixed rig. ${ }^{3}$ The Barbosa et al. (2007) PTMBuilder/RTIBuilder technique builds on work by Cula et al. (2003), Einarsson et al. (2004), Mudge et al. (2006) and Tchou et al. (2004) and simply requires a fixed camera, the object to record, a shiny red or black ball visible to the camera, and a moveable, stable light source. In addition to stability of the camera, light and object/surface, the light source must remain at a constant distance from the centre of the image. This slows the capture process as either a physical approach is required to maintain this distance such as a tape or laser range finder, or the lights must be laid out on a grid as determined by specialist software (PTM Planner: see Dellepiane et al., 2006). Barbosa et al. (2007) describe a software tool under development for providing interactive feedback to the person moving the light via spatial tracking assisted by a second glossy ball. We found that for large objects a fixed tape worked efficiently for a two-person capture team (what Zányi et al., 2007 describe as the "Egyptian Technique"). For very small objects we also employ a hemispherical mesh onto which the light source is placed.

\footnotetext{
${ }^{3}$ See Malzbender et al. (2009) for examples and software for Highlight PTM creation.
} 


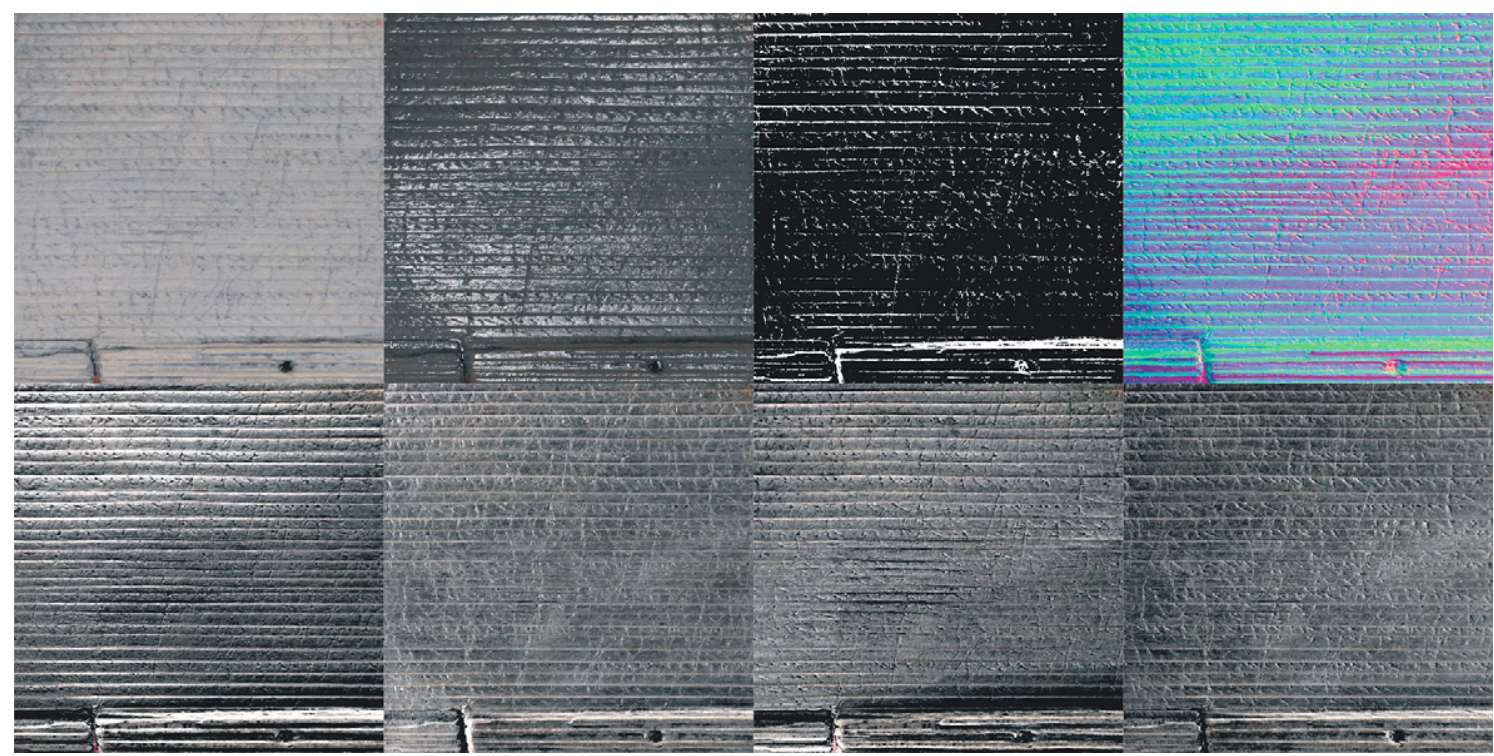

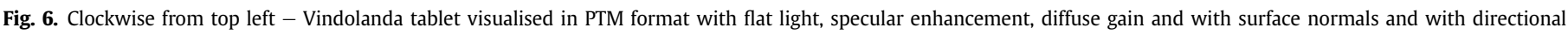
raking lights (from right, below, left and above).

Our highlight-based capture workflow uses a Nikon digital SLR set to take multiple shots at set intervals, and an external flash, fired either by wireless remote or via an extension cable. Alternatively a lighting source can be moved and the camera fired manually, or controlled by the flash (Fig. 2). We take a reference illumination and white balance check, largely to assess uniformity of illumination, via a Macbeth chart and uniform grey card. The photographs have lens distortion removed via camera calibration and Photomodeler Scanner software. This final stage is not required for production of the PTM but enables an even spatial distribution in the viewer. The HP PTMBuilder software searches each photograph for the fixed shiny ball and identifies the specular highlight on its surface. This then enables the incident light direction to be identified. The approach is extremely flexible and has received use in a range of cultural heritage contexts including rock art (Mudge et al., 2006) and 6th century AD Byzantine glass mosaics (Zányi et al., 2007), and most recently in our own work at Herculaneum (see Fig. 2 below; Earl, in press; Earl et al., 2009). The accuracy relative to a fixed rig is dependent upon the resolution of the capture of highlight, the definition and exposure of the highlight, and the variability in distance between light and the centre of the imaged plane. As with the fixed rig method it is common to carry out this approach in a darkened room or at night, although a combination of lens filters, fast shutter speeds and a high power flash can allow acquisition during bright daylight as well as negating the effects of ambient illumination (Mudge et al., 2006). The highlight-based technique is far easier (and cheaper) to implement and can record objects of any size, providing a suitable light source is available. As with the other software required for PTM creation and viewing the software is free to download and use for non-commercial uses. The RTIBuilder software updates the highlight-based processing technologies. It allows a variety of fitting algorithms to be employed and also captures detailed provenance information of vital importance to the subsequent management of the RTI data generated.

Where possible we capture stereo-pair PTM datasets. Although doubling the number of image captures these assist in building a surface model photogrammetrically if required at a later stage. ${ }^{4}$ In

\footnotetext{
${ }^{4}$ Zányi et al., 2007 describe capture of a stereo pair for subsequent processing of depth information.
}

a laboratory setup we also use a Konica Minolta vi910 close range laser scanner in order to record surface detail to supplement that available photogrammetrically. These datasets together complement the surface information held within the PTM format. Finally, we have implemented a Java based PTM viewer that can simultaneously display stereo-pair PTMs on our passive stereo projection system for interactive relighting in three-dimensions. This provides an additional sense of depth and light orientation perception.

\subsection{Quality of data captured via PTM approaches}

The PTM dataset has been analysed in detail with respect to its accuracy. In particular work by Dellepiane has shown that the resultant normal map is a close comparator to laser scan information (Dellepiane et al., 2006). Since we commonly produce a laser scan and/or photometric stereo surface model as a comparator to the PTM derived normals we aim to maximize the captured surface data. This is particularly significant where the surfaces recorded are fragmentary or only visible for short periods (e.g. in our ongoing work at Herculaneum). In addition to offering comparative metrics this enables definition of areas where the PTM is likely to be deficient such as areas of self-shadowing, where surface deviations are at a resolution lower than the pixel resolution. Conversely the laser scan dataset can be examined through comparison, for identification of scanning errors resulting from occlusion and this is likely to result in considerable improvement in surface data quality. Mudge further discusses the possibilities of integrating laser scan and PTM datasets for surface recording (Mudge et al., 2005). Recent work on increasing the accuracy of fitting PTMs by using robust fitting methods (Drew et al., 2009) have also increased the quality of surface normals by automatically separating out the effects of shadows and specular highlights. The quality of these normals outperform any existing collection method and can be incorporated in future PTM captures.

The PTM capture technique allows for any number and configuration of light sources over the object. Accuracy assessments have therefore also considered the optimum number of capture positions. Experimental results demonstrate that increased image numbers increase quality of surface normals produced (Hammer et al., 2002). Dellepiane compared 105 light positions to a $0.333 \mathrm{~mm}$ sample Konica Minolta vi910 laser scan of a 14th 


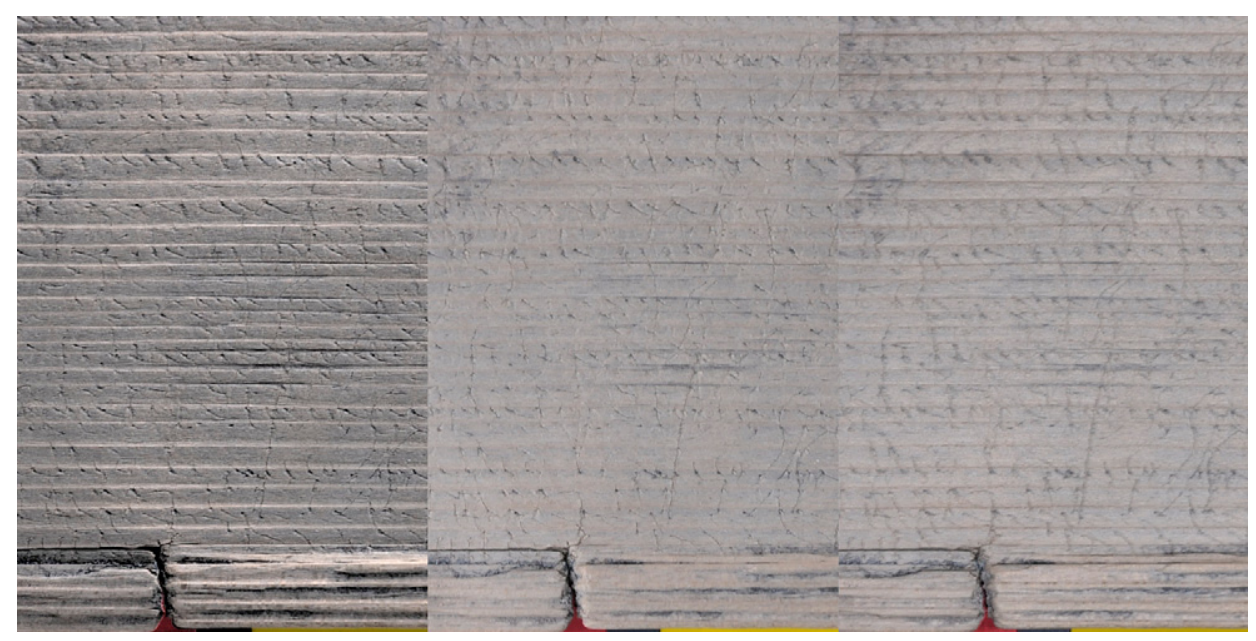

Fig. 7. A Vindolanda Tablet indicating, from left to right, the high, medium and low entropy views automatically extracted from the PTM.

century relief panel from the Museum of the Opera Primaziale in Pisa. The datasets were found to be spatially reliable (Dellepiane et al., 2006). In turn 65 light sources were found to produce nearequivalent results. In terms of lighting distribution best effects were obtained where the lights occupied the best fit over a hemispherical capture dome.

Our capture system has the advantage of variable light locations in the $\mathrm{XZ}$ plane, although $\mathrm{Y}$ values are limited by the number of fixed lights positions on the capture arm. The result is that we are able to produce eight concentric bands of lighting data at degree intervals of a minimum of 0.1 i.e. potentially 28,800 light positions. In a standard capture procedure we produce most PTMs with between 56 and 64 captures, but perform an additional check capture for key components of 224 captures.

\section{Results}

We have now applied Polynomial Texture Mapping in a wide range of archaeological contexts. In the following section we summarize the results of our recent applications in conservation recording and comparison, analysis of archaeological materials, archaeological representation and dissemination.

\subsection{PTM acquisition for conservation recording and comparison}

Our implementation of PTM in the field of conservation has so far focused on wooded artefacts, wall-paintings and metal. Elsewhere, PTM has begun to be used in particular in the production of conservation records for paintings (Padfield et al., 2005; Klausmeyer, 2005). Also in their work on the Antikythera Mechanism, Edmunds (Edmunds et al., 2006; Freeth et al., 2006; Malzbender and Gelb, 2009) have demonstrated the efficacy of the technique for imaging corroded metal surfaces. In this work the combination of PTMs and XRay tomography was able to increase the number of legible characters on the Antikythera Mechanism from 800 characters to over 2000 characters, allowing a new understanding of its functioning.

\subsubsection{Evaluation of conservation processes}

We have started a programme of capturing comparative data for assessing the application of Polynomial Texture Mapping to the recording and evaluation of conservation techniques. This is focussed on fragments of a Mesolithic trackway provided by the Hampshire and Wight Trust for Maritime Archaeology, and on a project with English Heritage (Fig. 3). In the latter a sample of previously waterlogged timber is being systematically Polynomial Texture Mapped and laser scanned at set periods in the conservation lifecycle. Initial results indicate that Polynomial Texture Mapping provides a means for consistent comparison of wooden artefacts (Karsten and Earl, in preparation). The PTMs produced over the project's lifetime will indicate whether deterioration and modification of the wood has a particular impact in areas such as tool marks and in the wood grain itself. Work is underway to automate processes for metric comparison of PTM datasets gathered at different times. Such comparisons are readily applied with laser scan data but the format of the normal maps generated by the PTM technique requires post-processing for comparison where there is no physical control over the orientation of the object.

\subsubsection{Herculaneum tablets and wall painting}

At Herculaneum the PTM technique has been applied to a range of other surface types. In parallel with work conducted by the Getty Conservation Lab (Sarah Court pers. comm.) we are exploring possibilities for rapid PTM capture of wall-paintings, in our case as they are exposed by ongoing conservation works at the Basilica Noniana (Fig. 2 above). We have also captured PTMs of legal tablets recovered from the Villa of the Papyri (Fig. 4). These wooden tablets were charred as a consequence of the burial of the site in AD79. The writing on the tablets is primarily preserved in the ink. The written material has been studied in depth using multispectral imaging (Booras and Seely, 1999; Chabries et al., 2003; Falcone et al., 2007). Our test with Polynomial Texture Mapping demonstrated that the differing surface textures of the wooden tablets and the ink lead to varying distribution of light by incident angle. ${ }^{5}$ Furthermore the PTM identifies surface damage and potential scratched markings that are not enhanced through multispectral imaging approaches using a consistent light direction. Our hope is that this work can be extended to a more extensive study in the near future, drawing on expertise in both areas (Knox et al., 2003; Web6). Not only does the PTM facilitate reading but it provides a conservation record of the surface geometry and reveals corresponding scratched information not otherwise recorded.

\footnotetext{
${ }^{5}$ A new study of painted Islamic ceramics with Rebecca Bridgman at the Fitzwilliam museum has explored the application of PTMs to capture the colour and surface properties even where surface texture is very similar across the artefact. See also the discussion of Fresnel effects at grazing incident angles in Malzbender et al. (2001).
} 

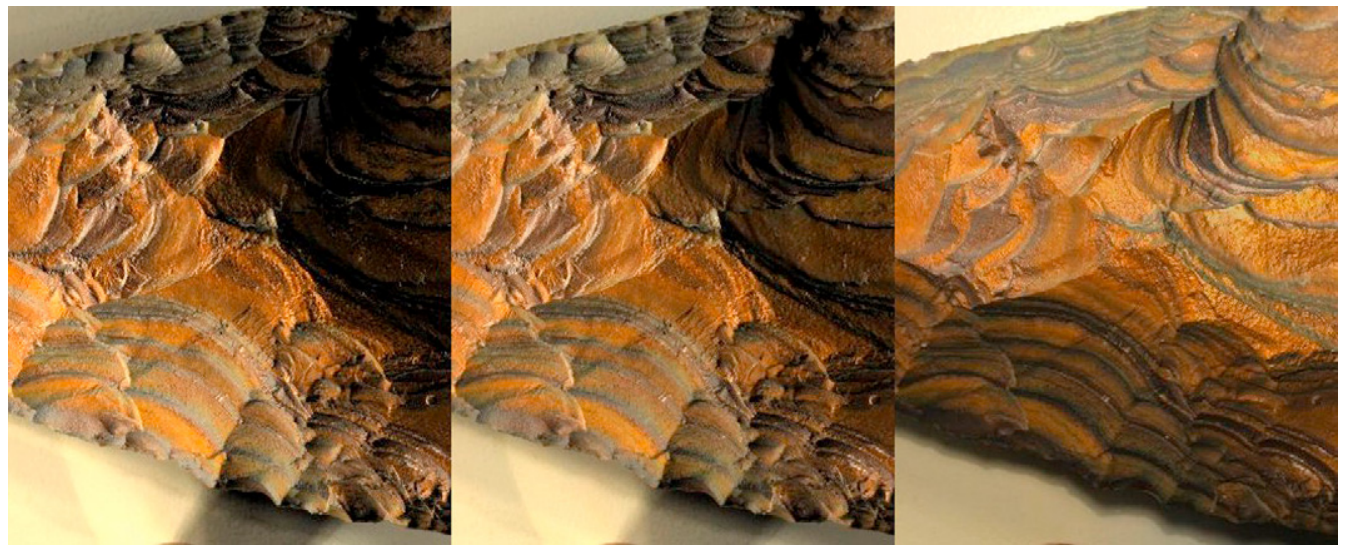

Fig. 8. A hand axe indicating, from right to left, the low, medium and high entropy lighting automatically extracted from the PTM.

\subsubsection{Corroded metal artefacts}

Corroded metal objects are particularly easy to visualise using PTM. We have captured various objects for the Portable Antiquities Scheme and for the University of Cambridge using the approach to good effect. In addition, a recent collaboration between the University of Southampton and the Fitzwilliam Museum has focused on the capture and comparison of laser scanning and Polynomial Texture Mapping of an 8th century BC bronze ship ram (Fig. 5). This artefact has recently been the subject of study by a range of specialists including material scientists, archaeologists, and experts in Classics and dating. Polynomial Texture Mapping results have provided a consistent record of the corrosion of the ram whilst the Konica Minolta vi910 laser scan provides the morphology. Although the scan is able to capture sufficient surface detail to represent areas of corrosion, the combination of surface geometric data, colour and texture captured simultaneously by PTM provides what we see as a vital counterpart.

\subsection{PTM acquisition for analysis of archaeological materials}

\subsubsection{Vindolanda tablets}

We have collaborated with the Centre for the Study of Ancient Documents (CSAD) at Oxford University and the British Museum in the capture of several hundred of the Vindolanda scratched writing tablets (Fig. 6; Web7). Results show that the tablet PTMs assist in segmenting wood grain from scratched portions of writing (see also Padfield et al., 2005, 2004). We have examined the tablets visually and experimented with edge detection filters on the normal maps derived from these PTMs with some good results. Subsequent work by us and experts from CSAD funded by an AHRC DEDEFI grant will evaluate the PTM as an input to ongoing work in automated grain removal/writing definition algorithms. Segmentation of materials from Bidirectional Reflectance Distribution Function (BRDF - see below) and PTM datasets has also been effectively demonstrated in work from UC Santa Cruz in a laboratory setting (Wang et al., 2009). These methods will extend well to archaeological applications, and in the specific case of recording Roman stylus tablets will enable the palimpsest may be further unpicked. This closely parallels the success in palaeontological PTMs in defining trace fossils with complex, multiple orientations (Hammer et al., 2002).

\subsubsection{Automated optimisation of PTM views}

The PTM process enables idealized lighting conditions to be defined automatically. Malzbender and Ordentlich (2005) describe an approach to automatic definition of optimal lighting direction based on measurements of image entropy derived directly from the

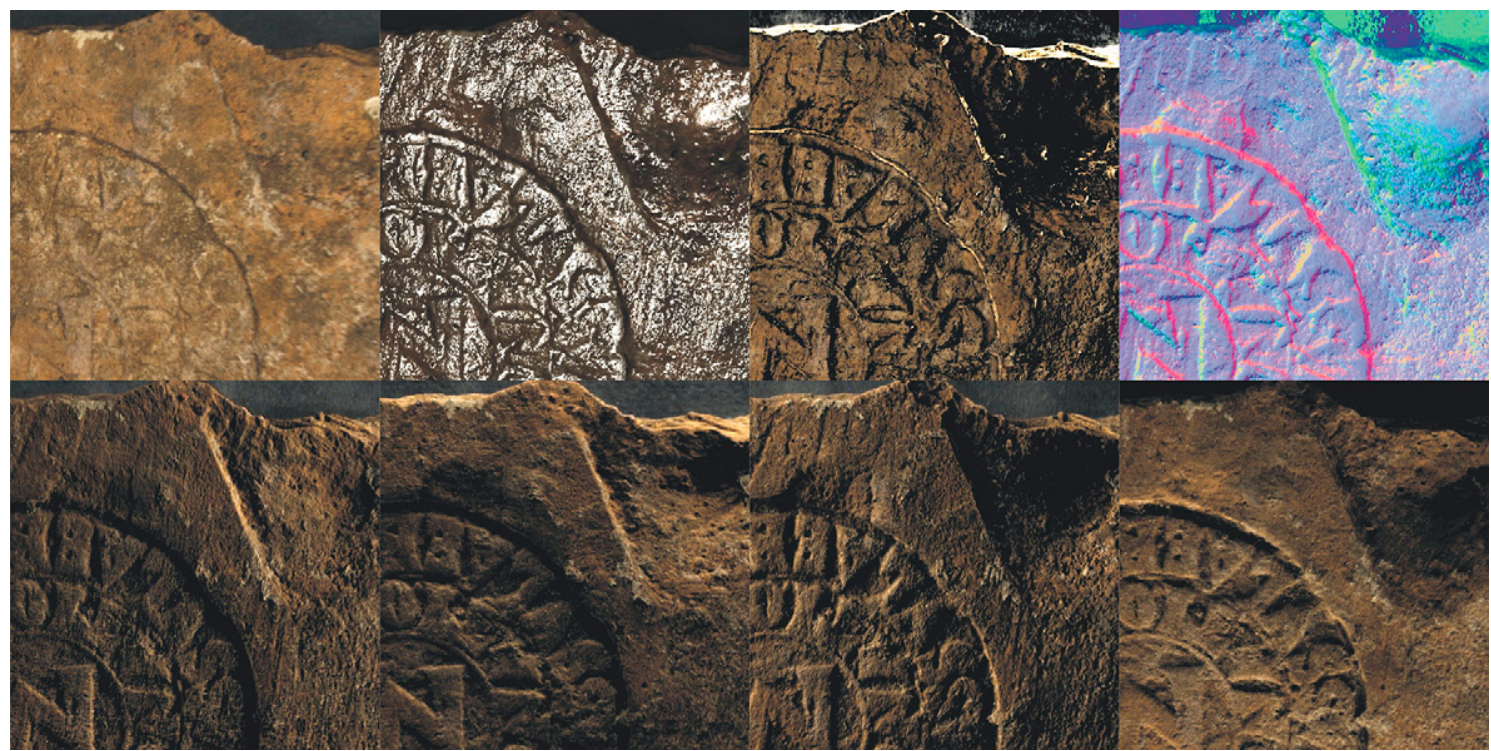

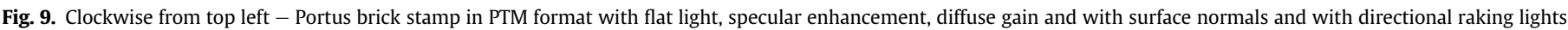
(from right, below, left and above).

Please cite this article in press as: Earl, G., et al., Archaeological applications of polynomial texture mapping: analysis, conservation and representation, J. Archaeol. Sci. (2010), doi:10.1016/j.jas.2010.03.009 


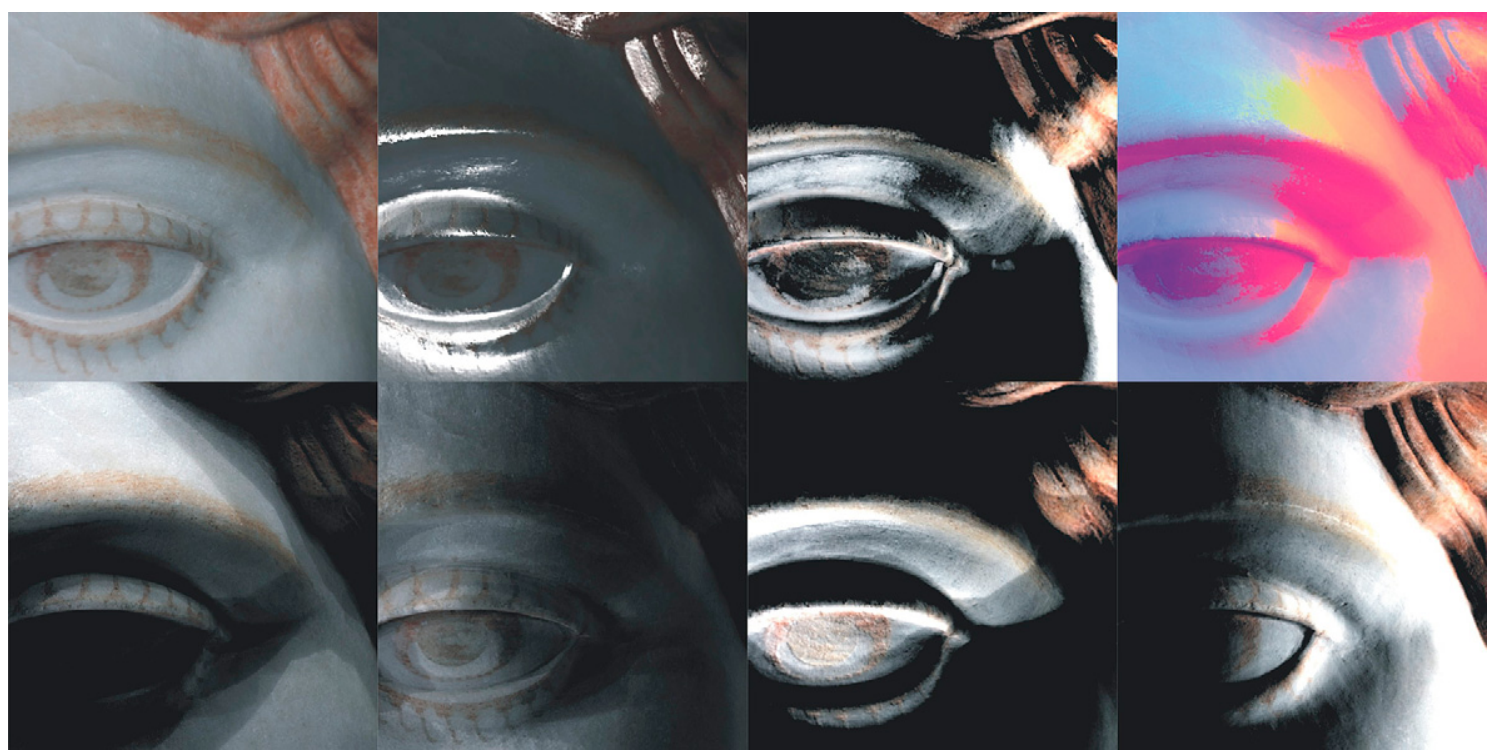

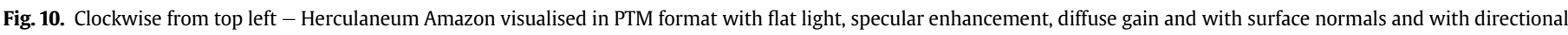
raking lights (from right, below, left and above).

PTM representation. This enables the automated preparation of relit images of objects that maximizes the visual information conveyed and potentially increases the definition of key details (see also Mudge et al., 2005). In Fig. 7 a single tablet is automatically virtually relit to produce low, medium and high entropy values. As part of our AHRC DEDEFI funded work on a large corpus of brick stamps (see below) we are developing an approach for automating this process across the whole collection so that we can produce a series of images that best represent the underlying data, and then pass these for automated image segmentation.

In related work Underhill-Stocks has used our technique to capture 105 PTMs of stone tools, ranging from hand axes and cores, to flake tools and flakes from sites in South Africa (Fig. 8; UnderhillStocks, forthcoming). His work explores the possibilities of PTM for lithic analysis, and in particular automated extraction and searching of worn attributes such as concave flake scars or convex/ pointed lips on flakes. ${ }^{6}$ A recent development of the reflection transformation approach to such lithic artefacts allows interactive, real-time capture and visualisation of an object's surface form, and enhancement of surface detail (Malzbender et al., 2006). Put simply, an object can be held and manually rotated within a hemispherical light dome. As it is manipulated a high-speed video camera, synchronized to the lighting rig, provides surface normal and reflectance data to the computer. This in turn displays an enhanced view in three-dimensions on screen.

\subsubsection{PTM as an archaeological recording tool}

The AHRC Portus Project (Earl and Keay, 2009) is focussed on the application and development of archaeological computing techniques, alongside the excavation and survey of the Palazzo Imperiale and the geophysical survey of the Roman port's hinterland. So far, PTMs have been generated by the Portus Project on site, as part of building recording process, as a comparator to digital photogrammetry, dense surface modelling and laser scanning, during finds recording, and for the dissemination of other kinds of digital data. For example we have produced virtual PTMs of our laser scan

\footnotetext{
${ }^{6} \mathrm{C}-\mathrm{H}-\mathrm{I}$ provide some clear examples of the benefits of visualisation of lithics at http://www.c-h-i.org/examples/ptm/gallery_stone_tools/index_ptm_stone_tools. html (Last Accessed 1 October 2009).
}

datasets for dissemination purposes by automatically generating a PTM capture system from the PTM light position file in software such as 3ds Max and animating the lights to enable capture of PTMs of any geometric data. This is a lightweight solution to intuitive dissemination of large scan datasets. We have also recorded in situ artefacts and other context details, supplementing standard Munsell colour and soil texture records. We have captured building material details primarily to assist in the construction of virtual models of the site (Earl et al., 2008), and captured building details to supplement time-of-flight laser scan data (Earl et al. forthcoming). Finally, in our field lab we have captured PTMs of coins, brick stamps (Fig. 9), architectural fragments, bone, shell, ceramics and metal and integrated these data via our ARK data management system (Web8). For rapid finds recording the fixed rig has proven invaluable, and during the initial post-excavation phase PTMs have offered unique access to finds no longer accessible to the specialists. In terms of analytical potential they have identified clear benefits in reading very eroded brick stamps and coins, examining stylistic aspects of epigraphic data, comparison of cut marks on bones, and osteological traits.

\subsection{PTM acquisition for representation and dissemination of archaeological data}

\subsubsection{Computer graphics}

In an ongoing project partly funded by an AHRC Collaborative Doctoral Award we are working with the Herculaneum Conservation Project (Web9), the University of Warwick and other partners to record and reconstruct the surface morphology of a 1st century BC Roman statue head preserved at Herculaneum by the eruption of Vesuvius in AD79 (Fig. 10; Earl et al., 2009). Polynomial Texture Maps were produced of the statue with the assistance of the Soprintendenza Speciale per i Beni Archeologici di Napoli e Pompei. This use of PTM has three goals: first to produce interactive views of the object, in order to enable straightforward distribution and appreciation of this beautiful painted artefact. The combination of subtle pigmentation and sculpture make for a perfect implementation of the PTM technique. The statue is almost brought to life by the interplay of light and colour across its surface. Indeed the lifelike nature of such statuary is itself a moot point (Beale et al., 2010).

The secondly goal is to analyse the appearance of painted Roman statuary in context, using physically accurate computer graphics. 

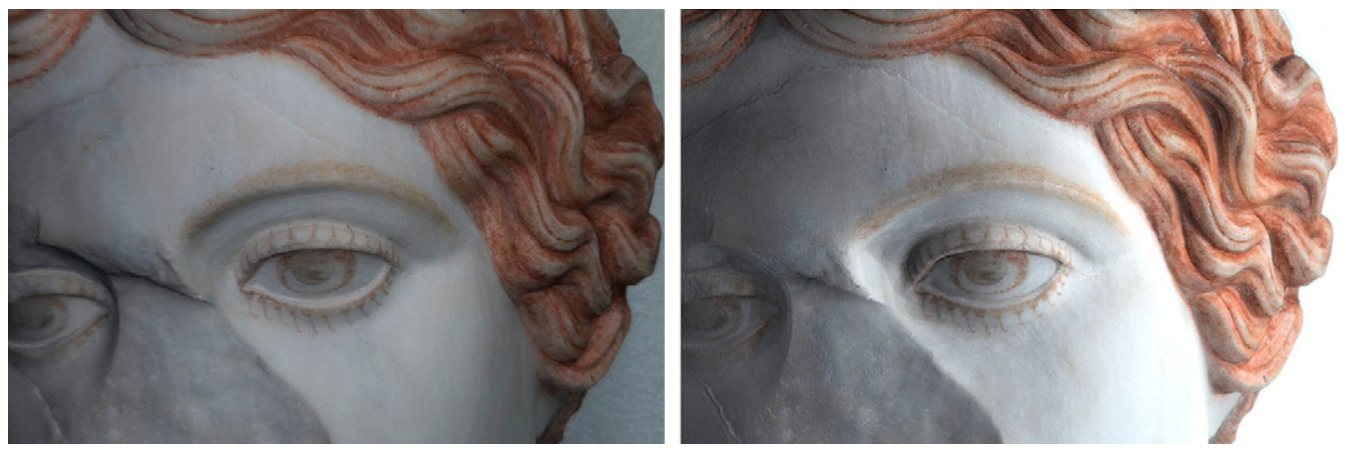

Fig. 11. Herculaneum Amazon relit with a single (left) and three (right) virtual lights.

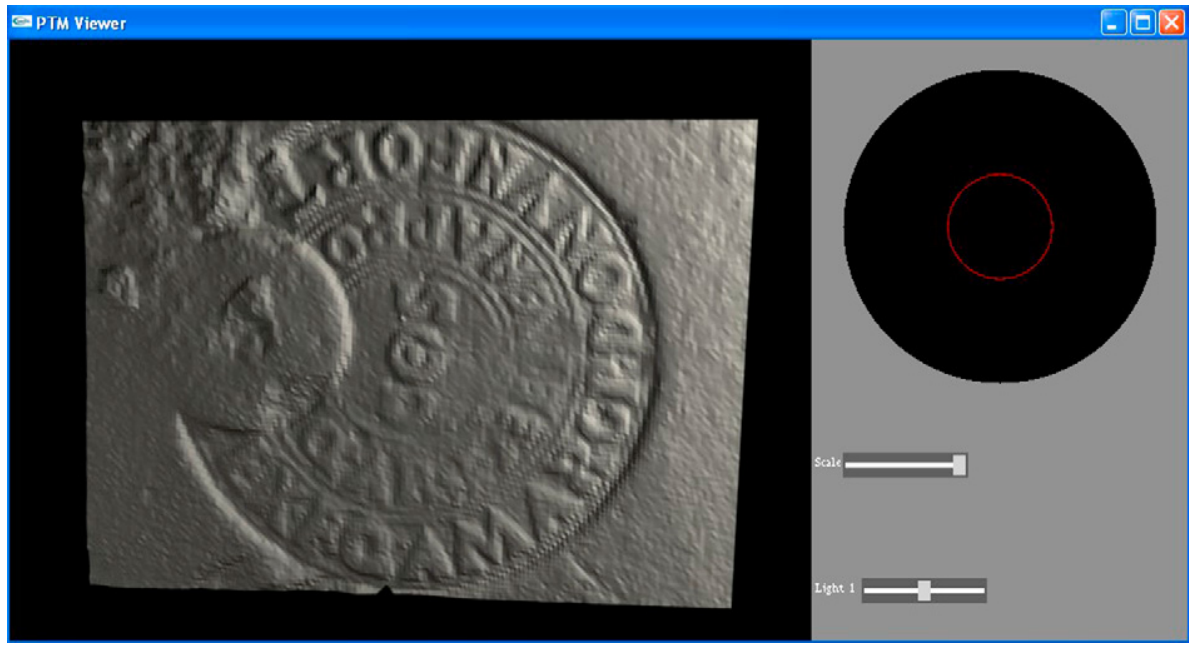

Fig. 12. Virtual PTM with laser scanned stamp dataset from Portus rendered for the PTM viewer.

PTM and related surface and sub-surface data are vital to achieving this aim. In order to produce physically accurate visualisations certain surface properties need to be captured. An extremely detailed laser scan of the head was produced by colleagues from the WMG (formerly Warwick Manufacturing Group) using a Metris laser scanner (Happa et al., 2009). This has a quoted accuracy of $50-60 \mu \mathrm{m}$ and is able to gather 80,000 spatially referenced points each second. The technique requires no registration and hence introduces none of the registration errors common to the laser scanning approach. Calibrated colour data was also gathered in high dynamic range and using a spectro-photometer. ${ }^{7}$ However such capture techniques do not record the impact of view orientation on the apparent pattern of light on the surface. To visualise the impact of this one may simply envisage the changing reflections of an object on a polished wooden table, or in a pool of water as you move around it. In graphics terms this relationship between view direction and surface appearance is described by the Bidirectional Reflectance Distribution Function (Hawkins et al., 2001; LaFortune et al., 1997; Müller et al., 2005) and is essential to any physically based analysis.

Since our interpretations of Roman aesthetics are necessarily theoretically complex - when producing computer graphic representations we are clearly not viewing Roman statuary,

\footnotetext{
7 Redman and Mudge (2007) describe the potential of integrating both PTM and multispectral data acquisition.
}

however accurately it is presented, through 'Roman eyes' - the closer we are able to come to the same physical perceptual stimuli the better we are able to introduce theoretically informed interpretations (Earl, in press). We can work entirely without this level of physical rigour and create a representation that is visually indistinguishable from reality but the interpretative benefits of this are less clear, beyond perhaps a reflexive study of our own representative bias. One aim of the Herculaneum Amazon project therefore is to develop methods for using the variety of PTMs captured of the statue to derive BRDF data, and also to employ additional BRDF capture techniques. ${ }^{8}$ Further work on collecting and representing PTMs collected under varying view direction appears in Gunawardane et al. (2009). The authors demonstrate the tradeoffs involved in collecting the massive collection of images required when varying both lighting direction and view direction, and provide guidance in keeping the data collection problems tractable.

The final reason for capturing PTMs of the statue has been to enable a structured comparison between the computer graphics simulations of the statue using such BRDF and PTM data, repainted physical replicas (Happa et al., 2009) and the real object (Zányi et al., 2007).

\footnotetext{
8 Mudge (2004); and Mudge et al. (2008) described mapping of PTM data onto model geometry, using the example of a captured cuneiform tablet that combined
} surface geometry generated via a structured light technique and PTM data. 


\subsubsection{Publication}

In the publication phase of the Herculaneum Amazon, Portus, and indeed any other archaeological projects, the production of perfectly lit but wholly artificial finds photographs is of considerable benefit. The HP PTM and RTI viewers enable multiple virtual light sources to illuminate the object's surface simultaneously, each with varying intensity. In effect this creates a virtual lighting rig and can be used to produce static relit photographs, an interactive PTM for use online (Web10), or indeed animations showing lights playing across the surface. In Fig. 11 we first light the Herculaneum statue described above with a standard directional light, and then augment this with two fill lights to reveal details to the left of the damaged nose and within the left eye socket.

\subsubsection{Other representations}

Previously we have described the use of PTM for presenting temporal, focal plane and a variety of other non-lighting based variations (see Malzbender et al., 2001). We have experimented with temporal PTMs as a means to represent a series of computer graphic images of sites. On the Portus Project and elsewhere we have employed the variable focal plane approach described in our computer graphic rendering. Furthermore we believe that the PTM provides an excellent means to convey landscape scale information, such as the results of visibility analysis. By stitching together multiple viewshed analyses, such that interaction with the viewer enables the archaeologist to see the pattern of visibility from a range of sampled locations in a landscape, more intuitive access is provided to the data. The main problem with this implementation has been the interpolation between viewer locations. Unless the number of samples corresponds to the pixel resolution the interpolation gives an incorrect representation of the pattern of visibility. Finally, we have constructed a digital version of our PTM rig. This enables us to load any digital surface dataset and produce a PTM automatically from it. To date this has been applied to laser scans of various object types (Fig. 12) and to geographic data as a means to enhance visualisation of landscape topography.

\section{Conclusions, future developments and wider potential}

The Polynomial Texture Mapping and the more general Reflectance Transformation Imaging suite of approaches have vast potential for archaeology. As an interactive visualisation tool they provide access to colour and texture in a way hitherto largely restricted to those in direct contact with the material culture. The Tate's (Web11) online exhibition demonstrates a public face role for this approach, supported by our own dissemination of PTMs from Portus online. We believe that museum interpretations could easily adopt this approach, providing an added layer of interaction.

Ongoing developments in computer science are set further to enhance the possibilities of RTI technologies. These include enhances to the algorithms used to process the input data (Wong et al., 1997; Mudge et al., 2008), methods for dealing with extremely large datasets (Dellepiane et al., 2006) and for generating three-dimensional or multi-view PTMs (Mudge, 2004; Mudge et al., 2006). Our ongoing AHRC DEDEFI project is also helping to address these and other issues.

As a record the PTM is cheap and quick to produce, simple to archive, ${ }^{9}$ and offers many of the benefits associated with laser scanning and digital photogrammetry. In combination we believe that these three technologies will perform an essential part of the archaeological recording process in years to come. Analytically, the

\footnotetext{
${ }^{9}$ An approach introduced in Mudge et al. (2005) and developed in Mudge et al. (2008) supports archiving procedures by introducing metadata capture to the PTM process. This describes the raw data captured and all subsequent processing steps.
}

ease of interaction has already stimulated new interpretations across the range of projects described. In collaboration with the Çatalhöyük Project (Web12) and with the projects mentioned above, we are further developing our understanding of the PTM as a conservationrecording tool and as part of our computer visualisation of the site. The production of computer graphics for the analysis of archaeological spaces and objects, and for their representation to a wider public will also benefit from the technology. We are very keen to explore other collaborations and in particular the application of this technology to other material types and to further interpretive goals, and look forward to the benefits that these may bring.

\section{Acknowledgements}

Earl's introduction to PTM came from a series of presentations by Cultural Heritage Imaging. We are all extremely grateful for their continued advice and support, for their comments on this paper, and during the development of the Southampton capture systems and in the evaluation of new approaches such as PTM Object Movie (POM or RTI multi-view) in 2007. Access to case studies and detailed discussions surrounding the implementation of PTM were supported by the British Museum, Cambridge University, Soprintendenza Speciale per $i$ Beni Archeologici di Napoli e Pompei, English Heritage, the Fitzwilliam Museum, Hampshire and Wight Trust for Maritime Archaeology, the Herculaneum Conservation Project, McGregor Museum, Oxford University, the Portable Antiquities Scheme, Southampton City Museums, and Wessex Archaeology. Funding for work has been through these same institutions, through generous contributions from our own institutions, and from the Arts and Humanities Research Council (Portus Project; DEDEFI), the British Academy, the Haverfield Bequest, the Hon. R. Underhill and the Hon. J. Taylor.

The first Southampton PTM rig was built by Eric Webb in the Mechanical Workshop, Electronics and Computer Science, University of Southampton. David Potts (Archaeological Computing Research Group) wrote the software for viewing PTM stereo pairs. Peter Smith (Electronics and Computer Science, University of Southampton) wrote the PTM capture software, with additional scripting and data capture by Hembo Pagi. Other members of the Archaeological Computing Research Group who captured PTM data included Gareth Beale, Catriona Cooper, Penny Copeland, Fiona Gamble, Eleni Kotoula and Lee Stone. David Underhill-Stocks is a PhD student in the Centre for the Archaeology of Human Origins, University of Southampton. Fiona Gamble's work was in collaboration with Andrew Jones (University of Southampton), Richard Bradley (University of Reading) and Aaron Watson. She was assisted by Hugo Lamdin-Whymark.

Nikon UK provided an API used in the initial development of the PTM capture process at the University of Southampton.

\section{References}

Barbosa, J., Sobral, J.L., Proença, A.J., 2007. Imaging techniques to simplify the PTM generation of a bas-relief. In: VAST'07: Proceedings of the 8th International Symposium on Virtual Reality, Archaeology and Cultural Heritage, UK, 2007, pp. 28-31.

Beale, G., Earl, G.P., Chalmers, A., Happa, J., Williams, M., 2010. Polychromy, Digita Simulation and an Amazon from Herculaneum. In: Proceedings of TRAC, 2009.

Booras, S.W., Seely, D.R., 1999. Multispectral imaging of the Herculaneum papyri. Cronache Ercolanesi 29, 96-99.

Chabries, D.M., Booras, S.W., Bearman, G.H., 2003. Imaging the past: recent applications of multispectral imaging technology to deciphering manuscripts. Antiquity 296, 359-372.

Cula, O.G., Dana, K.J., Murphy, F.P., Rao, B.K., 2003. Bidirectional imaging and modeling of skin texture. In: Proceedings of Texture 2003: The 3rd International Workshop on Texture Analysis and Synthesis, France, 2003, pp. 12-18.

Dellepiane, M., Corsini, M., Callieri, M., Scopigno, R., 2006. High quality PTM acquisition: reflection transformation imaging for large objects. In: Ioannides, M., Arnold, D., Niccolucci, F., Mania, K. (Eds.), VAST06: Proceedings of the 7th International Symposium on Virtual Reality, Archaeology and Cultural Heritage, Cyprus, 2006, pp. 179-186. 
Drew, M., Hajari, N., Hel-Or, Y, Malzbender, T., 2009. Specularity and shadow interpolation via robust polynomial texture maps. In: Proceedings of the British Machine Vision Conference, 2009.

Earl, G.P. Physical and photo-realism: The Herculaneum Amazon in: plenary session: fundamentos teóricos de la Arqueología virtual. In: Proceedings of Arqueologica 2.0 Seville 2009, in press.

Earl, G.P., Keay, S.J., 2009. The Portus Project. Available from: www.portusproject. org (last accessed: 01.05.09.)

Earl, G.P., Beale, G., Happa, J., Williams, M., Turley, G., Martinez, K., Chalmers, A 2009. A repainted Amazon. In: Proceedings of the 2009 EVA London Conference.

Earl, G.P., Beale, C., Keay, S.J., forthcoming. Archaeological computing for recording and presentation of Roman Portus. In: Keay, S.J., Paroli, L. (Eds.) Proceedings of the First Portus Workshop, held at the British School at Rome, March, 2008. British School at Rome Monographs.

Earl, G.P., Keay, S.J., Beale, G., 2008. Computer graphic modelling at portus: analysis, reconstruction and representation of the Claudian and Trajanic Harbours. In: Proceedings of EARSEL SIG Remote Sensing for Archaeology and Cultural Heritage, Rome, 2008.

Edmunds, M.G., Freeth, A., Bitsakis, Y., Moussas, X., Seiradakis, J., Magkou, E., Zafeiropoulou, M., Haycock, P., Hadland, P., Ramsay, A., Gelb, D., Malzbender, T.., 2006. The Antikythera mechanism - real progress through Greek/UK/US research. Recent Advances in Astronomy and Astrophysics, In: 7th International Conference of the Hellenic Astronomical Society ed. N.H. Solomos 2006 913-918.

Einarsson, P., Hawkins, T., Debevec, P., 2004. Photometric Stereo for Archeological Inscriptions. ACM SIGGRAPH. Sketches.

Falcone, L., Bloisi, F., Califano, V., Pagano, V., Vicari, L., 2007. Near infrared reflectography for deciphering obscured (whitewashed or ablated) epigraphs. Journal of Physics D: Applied Physics 40, 5547-5552.

Freeth, T., Bitsakis, X., Moussas, J., Seiradakis, A., Tselikas, A., Mangou, H. Zafeiropoulou, M., Hadland, R., Bate, D., Ramsey, A., Allen, M., Crawley, A., Hockley, P., Malzbender, T., Gelb, D., Abrisco, W., Edmunds, M., 2006. Decoding the ancient Greek astronomical calculator known as the Antikythera mechanism. Nature 444, 587-591.

Gunawardane, P., Wang, O. Scher, S., Rickard, I., Davis, J., Malzbender, T., 2009. Optimized image sampling for view and light interpolation. In: Proceedings of the 10th International Symposium on Virtual Reality, Archeology and Cultural Heritage, VAST 2009, Sept. 23rd, 2009.

Hammer, O., Bengtson, S., Malzbender, T., Gelb, D., 2002. Imaging fossils using reflectance transformation and interactive manipulation of virtual light sources. Paleontologia Electronica No. 1.

Happa, J., Williams, M., Turley, G., Earl, G., Dubla, P., Beale, G., Gibbons, G., Debattista, K., Chalmers, A., 2009. Virtual relighting of a Roman statue head from Herculaneum, a case study. In: Hardy, A., Marais, P., Spencer, S.N., Gain, J.E. Straßer, W. (Eds.), Proceedings of the 6th Afrigraph 2009. ACM.

Hawkins, T., Cohen, J., Debevec, P., 2001. A photometric approach to digitizing cultural artifacts. In: 2nd International Symposium on Virtual Reality, Archaeology, and Cultural Heritage, Glyfada, Greece, November, 2001.

Karsten, A., Earl, G.P. StirlingCastle Wood Recording Project: Polynomial Texture Mapping and Laser Scanning for the analysis of pre- and post-conservation wooden artefacts. English Heritage Research Report, in preparation.

Klausmeyer, P., 2005. Polynomial texture mapping and conserving a fire damaged oil painting by Lovis Corinth. Proceedings of the 2005 Seminar on Surface Metrology at WPI. Available from: http://www.me.wpi.edu/Research/SurfMet/ Seminar/Oct2005/philipklausmeyer.html (last accessed 01.05.09.).

Knox, K.T., Easton, Jr, R.L., 2003. Recovery of lost writings on historical manuscripts with ultraviolet illumination. In: Fifth International Symposium on Multispectral Color Science (Part of PICS 2003 Conference), Rochester, NY, pp. 301-306.

LaFortune, E.P.F., Foo, S.-C., Torrance, K.E., Greenberg, D.P., 1997. Non-linear approximation of reflectance functions. In: SIGGRAPH'97: Proceedings of the 24th Annual Conference on Computer Graphics and Interactive Techniques (New York, NY, USA, 1997). ACM Press/Addison-Wesley Publishing Co.,pp. 117-126.

Lundberg, M.L., 2006. New Technologies: Reading Ancient Inscriptions in Virtual Light. Available from: http://www.usc.edu/dept/LAS/wsrp/information/article. html (last accessed 01.05.09.)

Malzbender, T., Gelb, D., Wolters, H., Zuckerman, B., 2000. Enhancement of Shape Perception by Surface Reflectance Transformation. Tech. Rep. HPL- 2000-38R1. Hewlett-Packard Laboratories, Palo Alto, California.

Malzbender, T., Gelb, D., Wolters, H., 2001. Polynomial texture maps. In: SIGGRAPH 01: Proceedings of the 28th Annual Conference on Computer Graphics and Interactive Techniques (New York, NY, USA, 2001). ACM Press, pp. 519-528.

Malzbender, T., Ordentlich, E., 2005. Maximum Entropy Lighting for Physical Objects. Hewlett-Packard Technical Report HPL-2005-68. Available from:(last accessed 01.05.09.). http://www.hpl.hp.com/personal/Tom_Malzbender/papers/papers.htm.

Malzbender, T., Wilburn, B., Gelb, D., Ambrisco, B., 2006. Surface enhancement using real-time photometric stereo and reflectance transformation. In: Eurographics Symposium on Rendering 2006, Nicosia, Cyprus, June 26-28, 2006.

Malzbender, T., Gelb, D., 2001. HPLABS Polynomial Texture Mapping (PTM). Available from: http://www.hpl.hp.com/research/ptm/ (last accessed 01.05.09.).

Malzbender, T., Gelb, D., Barbosa, J., Sobral, J.L., Proença, A.J., 2009. Highlight-based PTMs. Available from: http://www.hpl.hp.com/research/ptm/ HighlightBasedPtms/index.html (last accessed 01.05.09.).

Malzbender, T., Gelb, D., 2009. Interactive Relighting of the Antikythera Mechanism. Available from: http://www.hpl.hp.com/research/ptm/antikythera_mechanism/ index.html (last accessed 01.05.09.)
Mudge, M., 2004. SIGGRAPH 2004 Conference Presentations, Web Graphics/Special Sessions/Panels, Cultural Heritage and Computer Graphics Panel. Soma Media, Publisher. ISBN1-58113-950-X.

Mudge, M., Voutaz, J.P., Schroer, C., Lum, M., 2005. Reflection transformation imaging and virtual representations of coins from the hospice of the grand St. Bernard. In: Mudge, M., Ryan, N., Scopigno, R. (Eds.), Proceedings of 6th International Symposium on Virtual Reality, Archaeology and Cultural Heritage (VAST2005). Eurographics Association,, pp. 29-39.

Mudge, M., Malzbender, T., Schroer, C., Lum, M., 2006. New reflection transformation imaging methods for rock art and multiple-viewpoint display. In: Ioannides, M., Arnold, D., Niccolucci, F. (Eds.), Proceedings of the7th International Symposium on Virtual Reality, Archaeology and Cultural Heritage (VAST2006). Eurographics Association, pp. 195-200.

Mudge, M., Malzbender, T., Chalmers, A., Scopigno, R., Davis, J., Wang, O., Gunawardane, P., Ashley, M., Doerr, M., Proenca, A., Barbosa, J., 2008. Imagebased empirical information acquisition, scientific reliability, and long-term digital preservation for the natural sciences and cultural heritage. Eurographics.

Müller, G., Bendels, G.H., Klein, R., 2005. Rapid synchronous acquisition of geometry and appearance of cultural heritage artefacts. In: Mudge, M., Ryan, N., Scopigno, R. (Eds.), The 6th International Symposium on Virtual Reality, Archaeology and Cultural Heritage VAST (2005).

Padfield, J., Saunders, D., Malzbender, T., 2004. Polynomial texture mapping: a new tool for examining the surface of paintings. Available from: http://cima.nglondon.org.uk/ptm/ (last accessed 01.05.09.)

Padfield, J., Saunders, D., Malzbender, T., 2005. Polynomial Texture Mapping: A New Tool for Examining the Surface of Paintings. ICOM Committee for Conservation.

Redman, J, Mudge, M., 2007. The simultaneous capture of spectral and textural information. In: Proceedings of the Society of Imaging Science and Technology Archiving 2007 Conference, Scott A. Stovall, General Chair, ISBN 978-0-89208270-4, pp. 2-11, 2007.

Tchou, C., Stumpfel, J., Einarsson, P., Fajardo, M., Debevec, P., 2004. Unlighting the parthenon. In: SIGGRAPH'04: ACM SIGGRAPH 2004 Sketches, USA, 2004. ACM Press, p. 80.

Underhill-Stocks, D. The Fauresmith: A Study of the Transition from the Earlier to Middle Stone Age in Northern South Africa (Working Title). Ph.D, University of Southampton, forthcoming.

(Web1) Cuneiform Digital Library Initiative. Available from: http://www.cdli.ucla. edu/about_cdli.html?section=partners (last accessed 01.05.09.)

(Web2) Aramaic Tablets Studied via PTM. Available from: http://www.physorg.com/ news174760375.html (last accessed 14.10.09.).

(Web3) InscriptiFact. Available from: http://inscriptifact.ncsa.uiuc.edu (last accessed 14.10.09.).

(Web4) Wessex Archaeology. Available from: http://www.wessexarch.co.uk/ (last accessed 01.05.09.).

(Web5) RTI Introduction. Available from: http://www.c-h-i.org/technology/ptm/ ptm.html (last accessed 01.05.09.)

(Web6) Archimedes Palimpest. Available from: http://www.archimedespalimpsest. org/ (last accessed 14.10.09.)

(Web7) Vindolanda Tablets Online. Available from: http://vindolanda.csad.ox.ac.uk/ (last accessed 14.10.09.).

(Web8) ARK - L-P Archaeology. Available from: http://ark.lparchaeology.com/ (last accessed 01.10.09.).

(Web9) The Herculaneum Conservation Project. Available from: http://www. herculaneum.org/ (last accessed 01.05.09.)

(Web10) Archaeological Computing Research Group PTM Examples. Available from: https://www.soton.ac.uk/archaeology/acrg/acrg_research_PTM.html accessed 14.10.09.).

(Web11) Frank Auerbach - Variable Light. Available from: http://www.tate.org.uk/ collections/ptm/default.htm (last accessed 01.10.09.).

(Web12) Reconstructing Çatalhöyük. Available from: http://www.soton.ac.uk/ archaeology/acrg/acrg_research_Çatalhöyük.html (last accessed 01.05.09.).

Wang, O., Gunawardane, P., Scher, S., Davis, J., 2009. Material slice classification using BRDF slices. Proceedings - IEEE Computer Society Conference on Computer Vision and Pattern (CVPR 2009), June 22, 2009.

Wenger, A., Gardner, A., Tchou, C., Unger, J., Hawkins, T., Debevec, P., 2005. Performance relighting and reflectance transformation with timemultiplexed illumination. ACM Transactions on Graphics 24 (3), 756-764.

Willems, G., Verbiest, F., Moreau, W., Hameeuw, H., Van Lerberghe, K., Van Gool, L. 2005. Easy and cost-effective cuneiform digitizing. In: Mudge, M., Ryan, N., Scopigno, R. (Eds.), Short and Project Papers Proceedings of 6th International Symposium on Virtual Reality, Archaeology and Cultural Heritage (VAST2005). Eurographics Association, pp. 73-80.

Wong, T., Heng, P, Or, S, Ng, W., 1997. Image-based rendering with controllable illumination. In: Rendering Techniques 97 : Proceedings of the 8th Eurographics Workshop on Rendering, June 16-18, 1997, ISBN 3-211-83001-4, pp. 13-22.

Woodham, R., 1980. Photometric method for determining surface orientation from multiple images. Optical Engineering 19 (1), 139-144.

Zányi, E., Schroer, C., Mudge, M., Chalmers, A., 2007. Lighting and byzantine glass tesserae. Proceedings of the EVA London Conference, 11-13 July 2007. Available from: http://www.eva-conferences.com/sites/eva-conferences.com/files/public/ active/0/22-Zanyi.pdf (last accessed 01.05.09.).

Zuckerman, B., 2004. Every dot and tiddle: a consideration of the limitations of computer imaging for the study of Dead Sea scrolls. In: Garber, Z., Zuckerman, B. (Eds.), Double Takes: Thinking and Rethinking Issues of Modern Judaism in Ancient Contexts. Studies of the Shoah, vol. XXVI. University Press of America. 